\title{
APOIO PSICOLÓGICO NA TERMINALIDADE: ENSINAMENTOS PARA A VIDA
}

\author{
Érika Arantes de Oliveira \\ Manoel Antônio dos Santos \\ Ana Paula Mastropietro"
}

\begin{abstract}
RESUMO. Em meio à crescente negação do sofrimento humano na contemporaneidade, a morte é cada vez mais banida do cotidiano e confinada aos hospitais. O presente trabalho tem por objetivo relatar uma experiência de intervenção psicológica junto a um paciente portador de leucemia linfoide aguda, uma doença potencialmente fatal, focalizando o acompanhamento proporcionado ao longo do seu tratamento, do diagnóstico à ausência de possibilidades terapêuticas, até o momento de sua morte, em uma enfermaria de um hospital geral, no contexto dos cuidados paliativos. O corpus do trabalho foi constituído pelo material clínico sistematizado a partir das intervenções psicológicas ocorridas no período de dois anos (2001-2003). Procurou-se compreender as fases do luto vivenciadas pelo paciente e a construção de possibilidades de intervenção psicológica na proximidade da morte. A possibilidade de acompanhar todas as etapas do adoecer, culminando com o momento da morte, configurou-se como uma experiência única e transformadora tanto para o paciente como para a psicóloga que o assistiu em sua despedida.
\end{abstract}

Palavras-chave: Terminalidade; hospital geral; cuidados paliativos.

\section{PSYCHOLOGICAL SUPPORT IN TERMINALITY: A LESSON FOR LIFE}

\begin{abstract}
In the middle of the growing denial of suffering in contemporary society, death is increasingly banished from the daily reality and confined to hospitals. This study aims to describe an experience of psychological intervention with a patient with acute lymphoid leukemia, a potentially fatal disease, focusing on the monitoring provided throughout their treatment, from diagnosis to lack of therapeutic possibilities, until the moment of his death in a ward of a general hospital in the context of palliative care. The body of the study consisted of the clinical material systematized on the basis of the psychological interventions carried out over a period of two years (2001-2003). An effort was made to understand the phases of mourning experienced by the patient and the possibility of psychological intervention as death approached. The possibility of being present throughout the stages of illness culminating in the moment of death represented a unique and transforming experience both for the patient and for the psychologist who assisted him at the time of his departure..
\end{abstract}

Key words: Terminality; general hospital; palliative care.

\section{APOYO PSICOLÓGICO EN LA TERMINALIDAD: ENSEÑANZAS PARA LA VIDA}

RESUMEN. En medio a la creciente negación del sufrimiento humano en el tiempo contemporáneo, la muerte es cada vez más banida del cotidiano y confinada a los hospitales. La finalidad de este estudio fue relatar una experiencia de intervención psicológica ante un paciente portador de Leucemia Linfoide Aguda, una enfermedad potencialmente fatal, focalizando el acompañamiento proporcionado sobre su tratamiento, su diagnóstico, la ausencia de posibilidades terapéuticas, por el momento de su muerte, en una enfermaría de un hospital general, en el contexto de los cuidados paliativos. El corpus del trabajo fue constituido por el material clínico sistematizado a partir de las intervenciones psicológicas, ocurridas en el período de dos años (2001-2003). Se intentó comprender las fases del lucho vivenciadas por el paciente y la posibilidad de intervención psicológica en la proximidad de la muerte. La posibilidad de estar presente en todas las etapas del adolecer,

Doutora em Psicologia. Psicóloga do Departamento de Psicologia e Educação da Faculdade de Filosofia, Ciências e Letras de Ribeirão Preto - USP, Brasil.

\# Doutor em Psicologia Clínica. Professor da Universidade de São Paulo, Brasil.

II Doutora em Ciências. Terapeuta Ocupacional do Hospital das Clínicas da FMRP-USP, Brasil. 
culminando con el momento de la muerte, se configuró como una experiencia única y transformadora, tanto para el paciente como para la psicóloga que la atendió en su despedida.

Palabras-clave: Terminalidad; hospital general; cuidados paliativos.

\begin{abstract}
Acho que para recuperar um pouco da sabedoria de viver seria preciso que nos tornássemos discípulos e não inimigos da Morte. Mas, para isso, seria preciso abrir espaços em nossas vidas para ouvir a sua voz. (Rubem Alves, 1991, p. 65).
\end{abstract}

A última década foi testemunha do crescimento da psico-oncologia. Esse campo surgiu da necessidade de se oferecer apoio emocional ao paciente com câncer, assim como aos seus familiares e profissionais envolvidos no tratamento (Angeromi-Camon, 2006); Gimenez, Carvalho - Magui \& Carvalho, 2006).

Apesar de ter sido implantada só recentemente nos serviços hospitalares, a união entre a psicologia e a oncologia já tem produzido resultados amplamente reconhecidos, por meio de aumentos significativos da sobrevida, melhora da qualidade de vida e fortalecimento psicológico para enfrentar a terminalidade quando se esgotam os recursos disponíveis para prolongar a sobrevida do paciente (Ferreira, 2004).

Os cuidados paliativos destinam-se aos pacientes designados como "terminais", com prognóstico de sobrevida inferior a seis meses (Ferreira, 2004). O apoio psicossocial no momento da terminalidade é fundamental, uma vez que, de acordo com os valores que regem a sociedade contemporânea, a morte é permeada de preconceitos e estigmas que envolvem uma série de elementos ameaçadores e persecutórios que aterrorizam o homem.

Segundo Morais (2000), esses elementos compreendem: 1) o conhecimento do destino: o homem é o único animal que tem consciência da própria finitude; 2 ) a solidão: a morte frequentemente se configura como um momento de solidão absoluta para o sujeito contemporâneo; 3) o desmonte da teia existencial: as redes afetivas, constituídas pela constelação de relacionamentos pessoais, são amputadas pela morte; 4) o caminho do sofrimento: o provável sofrimento envolvido no processo de morrer torna-o mais temido do que a própria morte; 5) a hipótese do nada, do desconhecido: o medo da possível inexistência de algo depois da vida e da dissolução da matéria; a morte concebida como um túnel sem sentido, que levaria o ser humano a parte alguma.

Talvez por sentir-se acossado por essas vicissitudes tão aterrorizantes, o homem apresenta uma recusa em pensar naturalmente na inevitabilidade da finitude. Tal recusa, entretanto, é posta em xeque no momento do diagnóstico de uma doença potencialmente fatal, sendo inevitável o confronto com a fragilidade, que se acentua com a evolução desfavorável do quadro clínico, levando à certeza da terminalidade.

Para Pierre (1998), esse primeiro contato com a doença teria como reações características típicas: o inconformismo, o choque inicial diante do diagnóstico e a exaustiva peregrinação de especialista em especialista, na expectativa de uma segunda opinião que traga uma mudança do diagnóstico e a reversão das expectativas sombrias. Segundo esse autor, é esperado que o doente passe por momentos de hostilidade e agressividade direcionadas ao meio, a Deus, aos seus familiares e aos profissionais que cuidam dele. $\mathrm{O}$ sentimento predominante é de impotência ante a possibilidade de perda da própria integridade física.

Esse contato brusco e penoso com a finitude, muitas vezes desencadeado pelo adoecimento, encontra expressão máxima no momento do agravamento das condições clínicas do paciente e da consequente caminhada rumo à terminalidade, daí ser um contato tão temido e evitado (Kubler-Ross, 2000). Segundo Kovács (2005), o medo é a resposta psicológica mais comum diante da morte.

Em contraposição à ideia da morte como o inimigo a ser combatido a qualquer custo articulou-se o movimento de cuidados paliativos como uma possibilidade de re-humanização do morrer (Torres, 2003). Dentro dessa concepção peculiar, que propõe uma ressignificação do olhar ocidental perante o morrer, os tratamentos visam ao bem-estar, mesmo quando a cura da enfermidade não seja mais possível (Kovács, 2003).

Segundo Callahan (1987), a consciência da necessidade dos cuidados paliativos representaria a terceira fase da história da medicina, por ele denominada de "cultura dos limites", que viria após a "fase dos cuidados" e a "fase da cura". Tal fase, caracterizada pela aceitação do limite, exigiria uma nova preocupação com a humanização da prática médica, primando pela simpatia (sentir-se junto ao outro) e pela empatia (sentir-se no lugar do outro), buscando favorecer o desenvolvimento de recursos 
que possam auxiliar na assistência à terminalidade (Schramm, 1999).

Para Callanan e Kelly (1994) e Hennezel (1995), uma das formas de amenizar essa experiência dolorosa é ouvir as comunicações de sentimentos dos que a estão vivenciando. Nesse contato com a iminência do fim da existência do outro é preciso partir do pressuposto de que, de alguma forma, quem está morrendo sabe disso e necessita de ajuda para compreender o que se passa consigo. A dificuldade maior que o profissional enfrenta nesses casos é a de ouvir essas comunicações sem se deixar impactar e paralisar diante da complexidade envolvida na tarefa de manutenção da interação com o paciente que vivencia essa situação. Essa empreitada exige uma condição de mente especial para poder oscilar livremente entre uma atitude de envolvimento existencial com o mundo vivido do outro e ao mesmo tempo preservar sua individualidade e identidade.

Segundo Callanan e Kelly (1994), é comum observar nos pacientes que vivenciam a terminalidade falas "confusas" e a presença de algumas metáforas recorrentes, como a da viagem. Para essas autoras, o importante é não desqualificar tais mensagens, pois acreditam que a proximidade com a morte faz com que os pacientes utilizem, frequentemente, uma linguagem simbólica para evocar suas experiências de vida e lidar com a situação da iminência da finitude.

Trata-se de um interagir que exige o máximo de liberdade interna para nos deixarmos levar pelos reiterados "convites" que o paciente nos faz para acompanhá-lo nessa travessia. A compreensão empática implica em poder entrar na pele do outro, porém é preciso ir além e poder olhar para o mundo a partir dos olhos do outro, isto é, como ele provavelmente o olharia. Para tanto é essencial termos uma postura de desprendimento e despojamento em relação aos nossos próprios valores, crenças e preconceitos, e total abstinência em relação aos desejos e expectativas de impor ao outro nossa própria perspectiva, sem a preocupação de chegar a algum lugar - por exemplo, acreditar que todas as conversações mantidas vão necessariamente resultar em alívio do intenso sofrimento emocional do paciente que está morrendo.

Isso requer do profissional a consciência de que é possível o paciente comunicar seus sentimentos por meio de imagens e representações verbais que surgem espontaneamente ao longo da interação que se estabelece. Essas imagens e falas não podem ser interpretadas literalmente (Rezende, 2000), mas devem ser compreendidas a fim de facilitar o processo de busca de sentidos e elaboração da experiência emocional.

O presente trabalho se propõe a relatar uma experiência de intervenção psicológica oferecida em contexto hospitalar, na qual se procurou desenvolver o tipo de interação descrito, no contexto dos cuidados paliativos, a partir da assistência a um paciente em seu processo de morrer.

\section{MÉTODO}

\section{Desenho do estudo}

O presente trabalho caracteriza-se como uma pesquisa clínica que utiliza como estratégia metodológica o estudo de caso. A pesquisa clínica, segundo Diers (1979), Brewer e Hunter (1989) e Miller e Crabtree (1992), está preocupada, em particular, com as questões inerentes à experiência clínica. Segundo Hulley et al. (2008), a experiência pessoal do pesquisador é fundamental para a escolha do objeto de pesquisa e para o desenvolvimento posterior do trabalho.

A opção pelo estudo de caso, cujas principais características são a análise em profundidade de um objeto e a preocupação com seu aspecto unitário, foi pautada na reconhecida importância desse tipo de estratégia de pesquisa, tanto para o aprimoramento científico como para o desenvolvimento de práticas psicológicas (Triviños, 1992; Peres \& Santos, 2005; Chizzotti, 2008).

\section{Corpus do trabalho}

O material apresentado no presente estudo compreende os conteúdos que emergiram no decorrer do processo de atendimento psicológico, individual, ocorrido no período de abril de 2001 a novembro de 2003. As intervenções psicológicas foram realizadas no contexto de um hospital geral, mais especificamente em um serviço de hematologia. $\mathrm{O}$ psicólogo integrava a equipe multidisciplinar desse serviço, que contava ainda com médicos, enfermeiros, fisioterapeuta, dentista, assistente social e nutricionista. Essa equipe se reunia semanalmente para a discussão dos casos e decisão de condutas terapêuticas.

Os atendimentos ocorriam no ambulatório, semanalmente, por ocasião dos retornos médicos agendados, bem como na enfermaria, junto ao leito, nos momentos em que o paciente encontrava-se internado, sendo que nesse caso os atendimentos eram diários. No ano de 2001 foram realizadas 62 sessões, englobando atendimentos em regime ambulatorial e na 
enfermaria; em 2002 ocorreram 49 encontros e em 2003 foram realizados 31 encontros, totalizando 142 sessões. Durante a trajetória do atendimento a sessão mais breve teve duração de 30 minutos e a mais longa de uma hora e 45 minutos, sendo essa o último encontro com o paciente, que faleceu imediatamente após esse atendimento. Todas as sessões foram transcritas imediatamente após o término dos atendimentos.

Foram obedecidos todos os cuidados éticos e as diretrizes contidas na normatização estabelecida pela Resolução CNS 196/96. O projeto foi aprovado pelo Comitê de Ética em Pesquisa do Hospital das Clínicas da Faculdade de Medicina de Ribeirão Preto (processo $n^{\circ}$ 4787/2002). O colaborador formalizou sua anuência com a realização do estudo mediante assinatura do Termo de Consentimento Livre e Esclarecido.

\section{Procedimento de análise}

O conteúdo das intervenções foi submetido a uma análise de conteúdo inspirada nos passos metodológicos descritos pela literatura disponível sobre abordagens qualitativas em pesquisa (Triviños, 1992). Para a análise dos dados, procedeu-se à ordenação das falas, extraídas das transcrições registradas pela psicóloga pesquisadora em seguida aos atendimentos realizados. As sessões foram lidas exaustivamente, na sequência cronológica em que ocorreram, o que possibilitou a organização e sistematização das ideias centrais. A seguir, selecionaram-se partes do material, buscando-se detectar as ideias relevantes que constituíam unidades de significado; desse modo, procedeu-se à descrição analítica, na qual os dados foram codificados e organizados nos temas que mais se relacionavam ao objetivo de favorecer uma compreensão da vivência de um paciente em situação de terminalidade. Finalmente, os resultados foram interpretados à luz de teóricos da área.

\section{RESULTADOS E DISCUSSÃO}

Os resultados foram sistematizados e serão apresentados em torno de três eixos temáticos, designados como: 1) A vida repensada à luz do adoecimento, 2) $O$ toque da doença e 3) $O$ último atendimento: as estações da viagem. Esses eixos permitem situar as vicissitudes enfrentadas após a descoberta da doença, demarcando os diferentes estágios vivenciados no processo de morrer. Procurouse compreender esse processo e a construção de possibilidades de intervenção psicológica na proximidade da morte.

Esses resultados serão antecedidos de uma breve apresentação do paciente.

\section{Caracterização do paciente}

O paciente, aqui denominado de Rafael (nome fictício), tinha 25 anos quando iniciou o atendimento psicológico com a psicóloga do serviço hospitalar onde fazia tratamento contra leucemia linfoide aguda. Era casado e pai de dois filhos, com seis anos e dois anos e meio, respectivamente. Sua esposa tinha a mesma idade que a dele e trabalhava como vendedora.

Rafael era católico e tornou-se evangélico no decorrer do tratamento. Havia estudado até a $4^{\mathrm{a}}$ série do Ensino Fundamental, era vendedor de um pequeno estabelecimento de sua cidade e tinha uma condição socioeconômica desprivilegiada. A doença e o tratamento o levaram a se afastar do emprego. Apesar de mostrar-se aparentemente abatido, na maior parte dos encontros sempre foi solícito ao contato.

\section{A vida repensada à luz do adoecimento}

O primeiro momento marcante do percurso psicoterapêutico de Rafael se deu quando rememorou o dia em que recebeu a comunicação do diagnóstico. Estabeleceu uma ligação entre os sentimentos despertados naquele instante em que soube do diagnóstico e os vivenciados em uma situação de sua adolescência.

\section{Parecia que um filme se passava na minha cabeça e tudo o que eu já sofria voltava com toda a força, eu me lembrava do que me aconteceu quando eu era mais jovem e da sensação de que o mundo caía na minha cabeça.}

Narrou, então, a história de sua vida até o momento. Sua mãe, quando solteira, trabalhava em uma fazenda no interior de Minas Gerais. Ainda muito nova mudara-se para São Paulo, onde começara a trabalhar como empregada doméstica. Acabou se envolvendo afetivamente com seu patrão, na época casado. Esse homem acabaria por assumir o relacionamento amoroso com sua mãe, abandonando a primeira família.

Com 16 anos Rafael descobriu, por intermédio da tia materna, que esse homem que coabitava com sua mãe não era seu pai biológico. Soube, então, de sua verdadeira origem: sua mãe se envolvera em Minas Gerais com o filho do fazendeiro, seu patrão, de quem engravidara, e havia se mudado para São Paulo para 
evitar um escândalo, que poderia advir caso a gravidez se tornasse assunto de conhecimento público.

O pior foi que a minha tia me contou para se vingar da minha mãe. Elas tinham brigado, nem sei direito o porquê, e resolveu me contar a verdade sobre a minha vida. Era a minha vida... ninguém pensou em mim: nem a minha tia, nem o meu pai e muito menos a minha mãe.

Esse foi o primeiro grande choque da vida de Rafael. A notícia foi tão "forte" para ele que, imediatamente após tomar conhecimento da verdade de suas origens, teve uma "crise convulsiva" (sic) e não se recorda de mais nada do que ocorreu naquele dia.

\begin{abstract}
Eu sei que na hora que a minha tia contou eu comecei a passar mal, passar mal mesmo... perdi todos os meus sentidos. Acredita que tive uma crise convulsiva? Nunca tinha tido, tive ali na frente dela. Foi horrivel.
\end{abstract}

$\mathrm{Na}$ tentativa de lidar com essa nova realidade, Rafael inicialmente apelou para o mecanismo de negação: a tia deveria estar mentindo para ele, por algum motivo queria difamar sua mãe e inventara essa história "sem pé nem cabeça".

Na hora eu pensei: é mentira! Parecia coisa de novela. Não tinha pé nem cabeça aquela história, achei mesmo que a minha tia estava inventando aquilo para se vingar da minha mãe, só para eu ficar contra ela.

Posteriormente, sobreveio a raiva: um ódio intenso a seu pai biológico por não tê-lo assumido, à sua mãe por ter mentido para ele durante todo aquele tempo e ao seu pai de criação por ter sido cúmplice nessa mentira.

Depois eu fui ver que a história era verdadeira, e aí não consegui nem olhar para a minha mãe. O pai que me criou foi um bom homem, me assumiu nunca me tratou como se eu não fosse seu filho, mas ele também mentiu para mim, e o pai de verdade então... esse nem quis me assumir.

Até que, gradualmente, pôde elaborar melhor a situação, vindo a aceitação do fato, principalmente pela possibilidade de ser beneficiado financeiramente por esse pai biológico, um senhor de muitas posses, caso a paternidade fosse reconhecida.
Fui descobrir mais desse meu pai biológico, e descobri que ele era cheio da grana, e eu na pindaíba... Pensei então: dos males o menor, se ele me reconhecer pelo menos de grana tô bem. Comecei a entender melhor também a atitude da minha mãe e do pai que me criou, eles só queriam me proteger... mas doeu!

A fase mais prolongada foi a da raiva e da revolta. Rafael conta que essa realidade lhe era insuportável na época e que naquele período ficou completamente desnorteado e "se perdeu" (sic), envolvendo-se em comportamentos de risco. $\mathrm{Na}$ busca de um paliativo para sua dor psíquica apelou para uso de bebidas, drogas e inúmeros relacionamentos fortuitos com mulheres. Comentou, sorrindo, que dessa fase guarda "uma tatuagem no braço e outra no coração" (sic).

Quando eu falo que tudo se resolveu não foi assim tão simples... nesse época eu saí de casa, dormia na casa de amigos, na praça, na rua mesmo... comecei a beber muito, a usar drogas, me tatuei. A vida para mim não valia mais grande coisa.

Sua "salvação" (sic) veio por meio de um envolvimento intenso com uma namorada, Rafaela, que posteriormente tornar-se-ia sua esposa e cujo nome é o feminino do dele. Conheceram-se durante sua fase de "perdição" (sic). Ela logo engravidou e depois de dois anos se casaram.

Sabe como eu saí do fundo do poço? Foi com a Rafaela. Até no nome a gente combina. Ela foi o meu anjo. Me ajudou a parar com a bebida, com as drogas, com a mulherada. Ela engravidou e só quis morar comigo quanto eu estivesse bem. Fomos casar depois de dois anos, mas ela nunca me abandonou.

$\mathrm{Na}$ época do estabelecimento do diagnóstico de Rafael o casal estava junto havia quatro anos e tinha tido um casal de filhos, um menino, que estava com seis anos, e uma menina, com dois anos e meio. Nesse momento em que assumira muitas responsabilidades familiares, viu-se necessitado da ajuda financeira do pai biológico, passando a procurá-lo com certa frequência. Relata que recebeu dele o apoio de que necessitava.

E depois de tudo isso, me encontrei. Tinha uma família, a minha família. Não tinha um bom emprego, sempre faltava alguma coisa. A Rafaela me ajudava, mas mesmo assim... nessa época o meu pai biológico me ajudou, ele não queria contato comigo, mas a grana ele me mandava. 


\section{$O$ toque da doença}

No início Rafael não acreditava, ou melhor, não podia acreditar na gravidade do diagnóstico e no seu reservado prognóstico. Dizia com frequência que havia um erro no seu exame, que ele só estava um pouco cansado, talvez anêmico, mas nada além disso.

\begin{abstract}
Eu estou aqui para fazer esse tratamento, mas ainda não me convenci que estou doente. Quem está doente, e com uma doença muito grave, passa mal, não consegue fazer o monte de coisas que eu faço. Ando mesmo mais cansado, mas é só anemia. Você vai ver como eles vão ainda descobrir que erraram...
\end{abstract}

As reações de Rafael estão de acordo com o que se espera encontrar nessa fase do adoecer. Para Pierre (1998), esse primeiro contato com a doença tem como reações características típicas expressões de inconformismo do tipo: "não, não pode ser comigo", o choque inicial diante do diagnóstico e a exaustiva peregrinação de especialista a especialista, na expectativa de uma segunda opinião que traga uma mudança do diagnóstico e a reversão das expectativas sombrias.

Procurou vários médicos na esperança de ouvir algo diferente do que lhe fora comunicado inicialmente. Comentou que o que o fez "acordar" foi a forma direta com que um dos médicos abordou a questão, dizendo-lhe que não iria enganá-lo, que ele tinha uma doença muito grave, um câncer no sangue, e que morreria logo se não procurasse recursos de tratamento especializado. Decidiu, então, vir para Ribeirão Preto.

\begin{abstract}
Antes de vir para cá, eu procurei um monte de médicos. Ainda tenho esperança de que descubram que erraram, mas teve um médico que me disse que o que eu tinha era muito grave e se eu perdesse tempo poderia morrer, e aí vim para cá. Na dúvida...
\end{abstract}

Assim que chegou ao Hospital das Clínicas Rafael foi internado. Nesse momento mencionou sua revolta com a vida. Relembrava com frequência o episódio ocorrido na adolescência, dizendo: "se não bastasse ter passado por tudo isso, agora mais essa da doença...". Questionava os desígnios divinos, proferindo em tom irônico que Deus gostava de todos os seus filhos, porém mais de uns do que de outros, uma vez que parecia que só ele sofria, que tantas pessoas ruins vivem bem enquanto ele parecia ter vindo ao mundo apenas para sofrer.

Então depois de tudo o que eu passei você acha que eu merecia mais isso? Falam que
Deus existe, que ama a gente... que amor é esse? Se eu pudesse eu não deixaria nem um filho doente, como ele sendo o Grande Pai faz isso comigo? Ou será que tem filhos que são mais filhos?

Nesse momento, ao relacionar o seu sofrimento da adolescência com o momento atual, Rafael trouxe novamente a questão do abandono paterno, da desproteção advinda da figura que deveria cuidar dele, referindo-se nesse momento ao Grande Pai (Deus).

De acordo com Pierre (1998) e Kubler-Ross (2000), é esperado que o doente passe nesse momento a experimentar outros sentimentos, tornando-se hostil e agressivo em relação ao meio e também a Deus, que parece não ter piedade de Sua criação.

Pouco a pouco as críticas se voltam para a falta de compreensão e compaixão dos profissionais e familiares. O sentimento predominante é de impotência. Foi comum nessa etapa a utilização de expressões do tipo: "Não, não houve engano, estou doente! Por que eu? O que eu fiz para merecer isto?" Ou: "Tantas pessoas ruins estão vivas, porque eu tenho que estar com essa doença?".

A permanência de Rafael na enfermaria foi longa. Em decorrência de ter adquirido uma infecção, necessitou ficar 42 dias internado. No começo da internação mostrava-se mais simpático com a equipe, depois de 10 dias na enfermaria começou a ficar mais introspectivo e menos disponível para o contato. Nessa ocasião o comportamento de Rafael foi tema de muitas discussões da equipe. No final da internação Rafael se mostrava mais agressivo. Foi solicitada uma avaliação da psiquiatria, que diagnosticou uma reação de ajustamento com sintomas ansiosos e depressivos. Como havia a possibilidade de receber alta em pouco tempo e o paciente havia aderido ao atendimento psicológico, optou-se por não introduzir medicamentos para o controle dos sintomas emocionais.

Depois da saída da enfermaria, Rafael aderiu a uma nova religião, acreditando intensamente na possibilidade de cura por meio da fé. Fazia promessas de eterna devoção a Deus e à família, caso se curasse, como se buscasse um método mágico de redenção existencial. Nesse processo penoso, mais do que a cura, pareceu lançar-se à busca da remissão de seus pecados. A nova religião funcionava como veículo que lhe permitiria dar forma ao anseio de transformação a partir do plano existencial.

Eu, depois que passei por tudo isso, passei a me apoiar mais na fé. Descobri Deus na minha vida. Eu tive uma vida muito mundana 
até agora e resolvi me entregar a uma nova vida. Tenho certeza que conseguirei a graça da cura!

Nesse momento, o paciente estabeleceu acordos com figuras que, aos seus olhos, representavam onipotência e supremacia, e que em sua fantasia tinham poder sobre o bem e o mal, sobre a vida e a morte, como os profissionais da equipe de saúde e Deus.

Resolvi que vou tratar melhor a equipe, vou seguir direitinho tudo o que eles me mandarem fazer... Vou ser o melhor paciente que já passou por aqui. Você vai ver!

Voltou-se para uma introspecção religiosa, que lhe permitiu tranquilizar-se e fortalecer-se para enfrentar a crise de modo mais efetivo. Nessa etapa de reorganização dos recursos defensivos pôde utilizar mecanismos que lhe garantiram a possibilidade de manter intacto o espírito de luta, a esperança na cura e no prolongamento da sobrevida. Rafael, de fato, modificou radicalmente seu comportamento: durante as sessões estava mais integrado e mostrava-se aparentemente resignado. Parecia estar poupando energia para buscar o prêmio maior: a recuperação da saúde.

Não obstante, vendo que seu quadro clínico não melhorava, pelo contrário, agravava-se a cada dia, Rafael ingressou no estágio de percepção da perda iminente. Nessa etapa o contato brusco com a finitude, que teve início nas primeiras manifestações do adoecimento, encontra sua máxima expressão. Nesse momento, o medo, a angústia e a introspecção aumentam (Kovács, 2005).

Rafael passou a questionar se não estava "pagando" pelos erros cometidos na juventude, se não estaria passando por tudo aquilo para a remissão de seus pecados e para que pudesse purificar sua alma alcançar a vida eterna.

Eu às vezes acho que não vai dar certo. E sabe que eu penso que talvez eu tenha que passar por isso? Que esse sofrimento pode ser para que eu tenha uma recompensa muito maior. Talvez eu tenha que pagar em vida os erros que eu fiz para que eu possa merecer a vida eterna. Só pode ser isso. Que outra explicação pode ter?

A dor psíquica aumentava à medida que constatava o início do fim. Sentimentos de culpa e insegurança, tristeza e perda eram retomados com maior intensidade. São características dessa fase de tomada de consciência quanto à irreversibilidade do processo: introspecção e reações de isolamento, recusa de receber visitas, labilidade emocional, choro imotivado e tristeza.

Eu tenho a minha fé, mas é duro pensar que tudo pode ter um fim. Estou meio esquisito, era para querer estar mais perto da minha família, mas o que eu quero é ficar sozinho, não consigo brincar com os meus filhos... Às vezes até acordo bem, mas aí dali a pouco estou chorando.

Nesse momento Rafael apresentava-se exausto, referindo com frequência que gostaria de ter sossego, que estava muito cansado daquela batalha contra a enfermidade.

Eu acho que fui vencido... não vejo mais como lutar contra o que está escrito que vai acontecer. Na verdade já perdi a batalha, estou exausto... sinal de que houve luta, né? Agora é pensar na outra vida, a que realmente interessa, a ETERNA.

Nessa fase os encontros com a psicóloga eram semanais e a esposa e os filhos de Rafael também passaram a ser atendidos por outro profissional da psicologia vinculado ao Serviço de Hematologia.

A esposa de Rafael se fez presente e participativa durante todo o tratamento dele, mas mostrava nessa fase também estar afetada por momentos de desânimo e de cansaço. Afirmava sentir que a batalha estava para ser encerrada e que a vitória não seria deles. Nesse estágio, parece que Rafael e sua esposa passaram a apresentar uma consciência muito clara da finitude dele, da destruição das teias afetivas que a morte promoveria, conforme assinala Morais (2000). Por outro lado, pareciam acalentados com o fato de que o "caminho do sofrimento" não fora tão solitário e com a crença de que não seria o nada que encontraria depois da dissolução da matéria (Kubler-Ross, 2000).

\section{$O$ último atendimento: as estações da viagem}

Nas últimas semanas de vida Rafael apresentou uma piora significativa no seu quadro clínico. Estava cada vez mais debilitado e a equipe médica já o considerava fora de possibilidades terapêuticas. Nessa etapa do tratamento pensou-se nos cuidados paliativos como possibilidade de re-humanização do morrer (Torres, 2003), visando ao bem-estar de Rafael, uma vez que a cura da sua doença não parecia mais ser possível.

Diante da necessidade de cuidados mais intensivos, Rafael foi hospitalizado em uma enfermaria de isolamento protetor, acompanhado pelo cunhado. A 
esposa havia ficado com ele até o dia anterior e fora para casa porque um dos filhos estava adoentado. Decorrida uma semana da sua internação, a psicóloga foi informada pelo médico de que houvera uma mudança no quadro clínico de Rafael: ele já não reconhecia ninguém e só verbalizava frases sem sentido.

De acordo com Callanan e Kelly (1994), é fácil rotular os comentários dos pacientes terminais como "confusos" e desqualificá-los. Quando isso ocorre, geralmente perde-se importante mensagem, uma vez que as pessoas, quando se aproximam da morte, frequentemente usam uma linguagem simbólica para evocar suas experiências de vida e lidar com a situação da iminência da finitude.

Infelizmente, as tentativas das pessoas de descrever o que estão vivenciando no momento da morte podem se perder, ser mal-interpretadas ou ignoradas, uma vez que essa comunicação pode ser obscura, inesperada ou extremamente simbólica. Isso leva Callanan e Kelly (1994, p. 36) a questionarem os limites da linguagem: "Será que a nossa língua é finita demais para descrever uma experiência tão infinita?" Já a possibilidade de "ouvir" essas mensagens finais capacita o profissional a tornar-se mais sensível às necessidades dos pacientes que estão morrendo, podendo proporcionar-lhes melhores cuidados, de modo a auxiliá-los no encontro com a morte.

A seguir serão relatadas passagens que se fizeram marcantes no último encontro entre a psicóloga e o paciente. $\mathrm{O}$ médico solicitou à psicóloga que avaliasse o paciente na enfermaria, naquele momento de extremo sofrimento e confusão mental. Rafael, ao perceber a entrada da psicóloga no quarto, reconheceu-a imediatamente e fez o seguinte comentário:

Boa tarde, Érika. Que bom que você chegou. Quando você entrou, você matou o cachorro preto que estava na porta me pondo medo (risos), você o colocou para correr... tô mais calmo agora...

Rafael, em seguida, narrou sucessivas viagens que teria realizado e em cada passagem parecia que ia se tornando mais e mais confiante para realizar aquela que seria sua última viagem.

De acordo com Callanan e Kelly (1994), as pessoas que estão morrendo geralmente utilizam metáforas de viagens para alertar aqueles que as rodeiam de que é chegado o tempo de morrer. Viajar é uma metáfora cristalina, frequentemente empregada para descrever a necessidade de despedir-se, morrer. As autoras salientam a importância de o profissional a quem o paciente endereça sua demanda de escuta não ser crítico, mas sensível às suas necessidades de ser acolhido em seu processo pessoal de elaboração do luto pela perda da vida. Rafael prosseguiu com o seguinte relato:

Sabe onde estou? Estou no Grand Canyon. Está cheio de bichos feios aqui: baratas, cobras, escorpiões. Estou num buraco, cheio de bichos e não consigo sair. Você está matando todos os bichos e me puxando pela mão.

Demonstrando estar muito agoniado durante o relato, acalmou-se no final. Permaneceu por alguns minutos em silêncio, porém logo iniciou uma "nova viagem”.

Agora estou no pico de uma montanha, tenho medo da altura. Olho para baixo, penso que vou cair, mas você me segura pelas mãos e me deixa ficar perto de você.

Dessa vez a angústia suscitada durante a elaboração do relato foi menor e, logo em seguida, Rafael iniciou uma "outra viagem".

Eu agora estou numa praia. Tenho medo das ondas. Estou quase me afogando (vivencia sensação de sufoco). Eu não estou sozinho, você está comigo e não me deixa afogar.

Esse último relato já foi produzido de forma mais tranquila, como se a angústia inicial houvesse se dissipado. Rafael tinha o semblante sereno ao terminar sua narrativa. Logo a seguir iniciou a descrição daquela que seria a sua última "estação":

Agora, agora eu tô no paraíso. Sabe quem está aqui? O John John Kennedy? (jovem celebridade norte-americana que havia morrido naquela semana, vítima de um acidente aéreo). E sabe a melhor? Ele é muito gente boa! (risos). Aqui é um lugar bonito, cheio de crianças, cheio de paz... quero ficar por aqui.

Ao ser questionado se a psicóloga estaria ou não com ele nesse lugar, ele disse: "Não, aqui você não pode entrar... você já me ajudou bastante. E vai continuar me ajudando aí debaixo... vai continuar me olhando e cuidando de mim".

Segundo Callanan e Kelly (1994), um dos temas predominantes no momento da morte é a presença tranquilizadora de alguém que não está mais vivo. Essa proximidade muitas vezes significa que o moribundo acredita que não vai morrer sozinho, que a morte não é necessariamente solitária. A companhia escolhida para 
esse estágio é de um jovem rico e famoso por sua beleza, alguém que havia morrido precocemente e que portava o nome, duplicado, do pai célebre, parecendo, assim, ter o valor simbólico de um tributo paterno. Assim, Rafael tentava escapar de seu destino de sujeito sem referências identitárias seguras, por não ter obtido inicialmente o reconhecimento e o nome paterno, além de ter sido privado do conhecimento de sua verdadeira origem.

Nesse momento Rafael se despede da companhia da psicóloga, uma vez que encontrara uma nova companhia que the parecia mais adequada naquela situação e que lhe serviria de apoio no ato da passagem. Aliado à presença de alguém não vivo, a visão de um novo lugar, frequentemente paradisíaco, pode trazer imensurável conforto para o paciente e é encarada como gesto final daquele que está morrendo.

Depois dessa fala Rafael emudeceu. Uma comunicação silenciosa foi estabelecida entre $o$ paciente e a psicóloga. Um silêncio sereno e tranquilo, acolhedor e reconfortante. $\mathrm{O}$ corpo inerte afundava-se no leito, porém o pensamento não parecia paralisado. Prestes a dizer sim à inexistência, a última verbalização de Rafael foi narrada em tom de gratidão:

Obrigado por tudo o que me fez. Pena que não poderei nunca retribuir o que fez por mim.

Passados 15 minutos, Rafael morreu.

\section{CONSIDERAÇÕES FINAIS}

Nesse estudo de caso de um paciente oncológico em fase terminal abordou-se a assistência psicológica no processo do morrer e suas implicações para a definição de estratégias que o ajudem a enfrentar e elaborar experiências emocionais intensas e inusitadas que são vivenciadas na fase anterior à morte.

Segundo Schramm (1999), ao contrário do que reza o senso comum, os doentes terminais precisam, na maioria das vezes, de maiores cuidados do que os doentes "curáveis", sendo que uma das necessidades especiais seria a disposição de acompanhá-los psicologicamente, quando desejado, para o enfrentamento mais tranquilo do que o autor denominou de "última viagem".

Nas últimas décadas as questões relativas a essa "última viagem" - aqui entendida como as últimas fases da vida, o processo de morrer, os gestos finais do existir - têm se convertido em objeto de reflexões não apenas filosóficas, mas também no âmbito da medicina, da bioética e das ciências humanas em geral (Schramm, 1999).

As "viagens" que Rafael compartilhou no desenlace de seu processo de morrer se revelaram uma aventura de busca de sentidos, para a qual os encontros com a psicóloga serviram como suporte necessário à sustentação da experiência de significação em processo. A escuta interessada e a companhia viva lhe possibilitaram manter o contato com áreas e fenômenos psíquicos raramente explorados e, a partir do contato prolongado com sua intimidade, pôde vocalizar um diálogo interior de profundas ressonâncias simbólicas perante o desafio talvez a grande batalha final - de buscar representar o impronunciável da morte.

As reflexões advindas da experiência relatada no presente estudo confirmam que a possibilidade de estar ao lado das pessoas que estão morrendo é uma experiência única e tocante, corroborando a afirmação de Rezende (2000), uma vez que essas pessoas podem transmitir informações esclarecedoras e, inclusive, mensagens de consolo diante do mais temido dos momentos. Como se pode observar no caso narrado, foram produzidos $\mathrm{e}$ compartilhados durante todo o atendimento, e especialmente na última sessão, conteúdos simbólicos altamente condensados, que aludiam ao processo de transformação e libertação do paciente, ao mesmo tempo em que anunciavam sua morte.

Em contrapartida, pôde-se oferecer ao paciente a percepção de que a mais radical das experiências humanas pode ser compartilhada, de modo que os sentimentos de solidão e derrota possam ser atenuados, dando lugar a momentos de cumplicidade, de intimidade e sofrimento psíquico dividido com o outro, o que pode proporcionar uma estranha leveza no lugar do peso insuportável do ser que encontra sua finitude (Rezende, 2000).

Afinal, o homem não nasce nem morre sozinho. É próprio da condição humana exigir a presença do semelhante nos atos inaugural e final da existência. $\mathrm{O}$ atendimento psicológico pode se afigurar como uma cidadela fortificada, um lugar de resistência diante do desamparo humano ante o enigma da morte, um espaço de encontro com a significação necessária para que se complete o ciclo vital e se possa dobrar o limiar entre vida e morte.

Nessa direção, o presente estudo permite destacar a importância da assistência psicológica para que se possa cumprir um dos princípios básicos da filosofia de trabalho dos cuidados paliativos, que é oferecer qualidade de vida nos momentos que precedem a terminalidade, desde o diagnóstico até o momento da morte concreta.

Escutar as mensagens finais desses pacientes de um modo desprovido de crítica e munido de um genuíno desejo de entender qual é sua real necessidade em cada estágio do processo de despedida da vida pode, segundo Callanan e Kelly (1994), proporcionar-lhes uma avenida para uma morte tranquila. 
Essas mensagens podem criar uma moldura dentro da qual a morte deixa de ser vista e vivida como um fato solitário, amedrontador, intimidador e dominador. Essa transformação psíquica da experiência dolorosa é possível quando se tem o suporte da presença vivificante do outro, quando se pode contar com a brandura de uma palavra de conforto, o consolo de uma companhia discreta e não invasiva, suficientemente acolhedora e capaz de discernir como, quando e por que acompanhar no período da terminalidade.

Por outro lado, o contexto conversacional que se cria com a produção dessas narrativas de despedida também permite desvelar, perante o profissional de saúde mental, as dimensões de sua própria fragilidade enquanto ser humano - e, como tal, um ser voltado para a morte, o que inclui sua dimensão de mistério e irredutibilidade às categorias racionais. Sustentar um espaço em que o paciente possa dar contornos para essa necessidade de subjetivação da extinção de sua própria existência contribui para a qualidade de vida.

O objetivo dos cuidados paliativos é oferecer ao paciente e à sua família a melhor qualidade de vida possível no tempo que antecede a morte. Como mostra Ferreira (2004), a ênfase é dada para a assistência à dor e a outros sintomas aflitivos, mas é fundamental integrar os aspectos físicos, psicológicos e espirituais do paciente.

Assim, percebemos que aqueles que têm o privilégio de estar próximos de alguém que esteja morrendo podem também fazer desse contato uma fonte de conforto ante a inevitabilidade da morte. Como diz Hennezel (1995), a morte intima os que vão morrer a ensinarem a viver.

\section{REFERÊNCIAS}

Alves, R. (1991). A morte como conselheira. Em R. M. S. Carsola (Org.), Da morte: estudos brasileiros (pp. 65-76). São Paulo: Papirus.

Angeromi-Camon, V.A. (2006). O resignificado da prática clínica e suas implicações na realidade da saúde. Em Angerami- Camon, V. A. (Orgs.), Psicologia da saúde: Um novo significado para a prática clínica. (pp. 7-23). São Paulo: Pioneira.

Brewer, J. \& Hunter, A. (1989). Multimethod research: a syntesis of styles. Califórnia, USA: Sage: Newbury Park.

Callahan, D. (1987). Setting limits: medical goals in an aging society. New York, USA: Simon \& Schuster.

Callanan, M. \& Kelley, P. (1994). Gestos finais: compreendendo a consciência, necessidades e mensagens dos doentes terminais. São Paulo: Nobel.
Gimenez, M. G., Carvalho - Magui, M. M. M. J. \& Carvalho, V. A. (2006). Um pouco da história da Psico-oncologia no Brasil. Em Angerami- Camon, V. A. (Orgs.), Psicologia da saúde: Um novo significado para a prática clínica. (pp.48-72). São Paulo: Pioneira.

Chizzotti, A. (2008). Pesquisa em Ciências Humanas e Sociais. $9^{\mathrm{a}}$. ed. São Paulo: Cortez Editora.

Diers, B. D. (1979). Research in nursing practice. Philadelphia, USA: J. B. Lippincott.

Hennezel, M. (1995). La morte intima los que van morir nos enseñam a viver. Buenos Aires, Argentina: Sudamericana.

Hulley S. B., Cummings, S. R., Browner, W. S., Grady, D., Hearst, N. \& Newman, T. B. (2008). Delineando a pesquisa clínica: uma abordagem epidemiológica. $3^{\mathrm{a}}$ ed, Porto Alegre: Artmed.

Kovács, M. J. (2005). Educação para a morte. Psicologia, Ciência e Profissão, 25(3), 484-497.

Kovács, M. J. (2003). Bioética nas questões da vida e da morte. Psicologia USP, 2(14), 115-167.

Kubler-Ross, E. (2000). Sobre a morte e o morrer. (P. Menezes, Trad.), São Paulo: Martins Fontes. (Original publicado em 1969).

Miller, W. L. \& Crabtree, B. F. (1992). Primary care research a multimethod tipology and qualitative roadmape. Em B. F. Crabtree \& W. L. Miller (Eds), Doing qualitative research. (pp.328). Newbury Park: Sage.

Morais, R. (2000). Homem e morte: visão antropológico-filosófica e senso comum. Em V. L., Rezende (Org.), Reflexões sobre a vida e a morte: abordagem interdisciplinar do paciente terminal. (pp. 95-104). Campinas: Editora da Unicamp.

Peres, R. S., Santos, M. A. (2005). Considerações gerais e orientações práticas acerca do emprego de estudos de caso na pesquisa científica em Psicologia. Interações, 10(20), 109-126.

Pierre, C. (1998). A arte de viver e morrer. São Paulo, SP: Ateliê Editorial.

Rezende, V. L. (2000). Os últimos momentos: abordagem psicológica para pacientes terminais: Em V. L. Rezende (Org.), Reflexões sobre a vida e a morte: abordagem interdisciplinar do paciente terminal (pp.69-77). Campinas: Editora da Unicamp.

Ferreira, M. L. (2004). Medicina paliativa e atendimento psicológicohospitalar. Psicologia Clínica, 6(1), 163-172.

Schramm, F. R. (1999). Cuidados paliativos: aspectos filosóficos. Revista Brasileira de Cancerologia, 45(4), 57-63.

Torres, W. C. A. (2003). Bioética e a Psicologia da Saúde: reflexões sobre questões de vida e morte. Psicologia: Reflexão e Crítica, 3(16), 475-482.

Triviños, A. N. S. (1992). Introdução à pesquisa em ciências sociais: a pesquisa qualitativa em educação. São Paulo: Atlas.

Recebido em 25/07/2008 Aceito em 30/03/2009

Endereço para correspondência:

Érika Arantes de Oliveira. Av. Bandeirantes, 3900, Monte CEP 14040-901, Ribeirão Preto-SP, Brasil.E-mail:erikaao@ffclrp.com.br. 